\title{
EDITORIALS
}

1227 The quest for the grail: multidimensional efforts for understanding and targeting severe asthma Mina Gaga, Paul L.P. Brand and Neil C. Thomson

1232 Weaning from inhaled corticosteroids in COPD: the evidence

Samy Suissa and Andrea Rossi

Knowing when to stop: inhaled corticosteroids and COPD

Peter Calverley

1239 Targeted therapy for lung cancer

Anne-Pascale Meert and Jacques Cadranel

Lung allograft loss: naming helps seeing... and vice versa!

Peter Dorfmüller and Tom Kotsimbos

$1247 \quad$ Gaining insights into pulmonary hypertension in respiratory diseases Joan Albert Barberà and Isabel Blanco

1251 Completely scoobied: the confusing world of temperature and pollution effects on sleep apnoea Nathaniel S. Marshall and Christine T. Cowie

Eosinophilic granulomatosis with polyangiitis (formerly Churg-Strauss syndrome): where are we now? Matthieu Groh, Christian Pagnoux and Loïc Guillevin

1259 Should the treatment of advanced lepidic adenocarcinoma be adapted to the pathological subtype? Marianne Paesmans

1262 Asthma education: an essential component in asthma management

Louis-Philippe Boulet

Pneumococcal conjugate vaccine for adults: “It's tough to make predictions, ..."

Mathias W. Pletz and Tobias Welte

\section{European lung corner}

1269 A message from the ERS President and the ERS Secretary for EU Affairs

Elisabeth Bel and Jean-Paul Sculier

1270 Chronic respiratory diseases and lung cancer research: a perspective from the European Union Adoración Navarro-Torné, María Vidal, Dominika K. Trzaska, Lara Passante, Aldo Crisafulli, Hannu Laang, Jan-Willem van de Loo, Karim Berkouk and Ruxandra Draghia-Akli

\section{ORIGINAL ARTICLES}

\section{COPD}

1281 Benefits of physical activity on COPD hospitalisation depend on intensity

David Donaire-Gonzalez, Elena Gimeno-Santos, Eva Balcells, Jordi de Batlle, Maria A. Ramon,

Esther Rodriguez, Eva Farrero, Marta Benet, Stefano Guerra, Jaume Sauleda, Antoni Ferrer, Jaume Ferrer Joan A. Barberà, Robert Rodriguez-Roisin, Joaquim Gea, Alvar Agustí, Josep M. Antó,

Judith Garcia-Aymerich and the PAC-COPD Study Group

\section{Asthma and occupational lung disease}

Incidence of rhinitis and asthma related to welding in Northern Europe

Torgeir Storaas, Jan-Paul Zock, Ana Espinosa Morano, Mathias Holm, Eythor Bjørnsson, Bertil Forsberg,

Thorarinn Gislason, Christer Janson, Dan Norback, Ernst Omenaas, Vivi Schlünssen, Kjell Torén and

Cecilie Svanes

\section{Asthma}

1298 A repeated short educational intervention improves asthma control and quality of life Vicente Plaza, Meritxell Peiró, Montserrat Torrejón, Monica Fletcher, Antolín López-Viña, José María Ignacio, José Antonio Quintano, Santiago Bardagí and Ignasi Gich on behalf of the PROMETHEUS Study Group

Clinical and inflammatory characteristics of the European U-BIOPRED adult severe asthma cohort Dominick E. Shaw, Ana R. Sousa, Stephen J. Fowler, Louise J. Fleming, Graham Roberts, Julie Corfield, loannis Pandis, Aruna T. Bansal, Elisabeth H. Bel, Charles Auffray, Chris H. Compton, Hans Bisgaard, Enrica Bucchioni, Massimo Caruso, Pascal Chanez, Barbro Dahlen, Sven-Erik Dahlen, Kerry Dyson Urs Frey, Thomas Geiser, Maria Gerhardsson de Verdier, David Gibeon, Yi-ke Guo, Simone Hashimoto, Gunilla Hedlin, Elizabeth Jeyasingham, Pieter-Paul W. Hekking, Tim Higenbottam, Ildikó Horváth,

Alan J. Knox Nobert Krug, Veit J. Erpenbeek, Lars X. Larsson, Nikos Lazarinis, John G. Matthews,

Roelinde Middelveld, Paolo Montuschi, Jacek Musial, David Myles, Laurie Pahus, Thomas Sandström, Wolfgang Seibold, Florian Singer, Karin Strandberg, Jorgen Vestbo, Nadja Vissing, Christophe von Garnier, lan M. Adcock, Scott Wagers, Anthony Rowe, Peter Howarth, Ariane H. Wagener, Ratko Djukanovic,

Peter J. Sterk and Kian Fan Chung on behalf of the U-BIOPRED Study Group 


\section{ORIGINAL ARTICLES (CONTINUED)}

\section{Asthma and paediatric pulmonology}

The burden of severe asthma in childhood and adolescence: results from the paediatric U-BIOPRED cohorts Louise Fleming, Clare Murray, Aruna T. Bansal, Simone Hashimoto, Hans Bisgaard, Andrew Bush, Urs Frey, Gunilla Hedlin, Florian Singer, Wim M. van Aalderen, Nadja H. Vissing, Zaraquiza Zolkipli, Anna Selby, Stephen Fowler, Dominick Shaw, Kian Fan Chung, Ana R. Sousa, Scott Wagers, Julie Corfield, Ioannis Pandis, Anthony Rowe, Elena Formaggio, Peter J. Sterk and Graham Roberts on behalf of the U-BIOPRED Study Group

\section{Paediatric pulmonology}

Infant respiratory infections and later respiratory hospitalisation in childhood Hannah C. Moore, Graham L. Hall and Nicholas de Klerk

\section{Cystic fibrosis}

miR-17 overexpression in cystic fibrosis airway epithelial cells decreases interleukin-8 production Irene K. Oglesby, Sebastian F. Vencken, Raman Agrawal, Kevin Gaughan, Kevin Molloy, Gerard Higgins, Paul McNally, Noel G. McElvaney, Marcus A. Mall and Catherine M. Greene

\section{Sleep}

Association of short-term ozone and temperature with sleep disordered breathing Gerhard Weinreich, Thomas E. Wessendorf, Noreen Pundt, Gudrun Weinmayr, Frauke Hennig, Susanne Moebus, Stefan Möhlenkamp, Raimund Erbel, Karl-Heinz Jöckel, Helmut Teschler and Barbara Hoffmann on behalf of the Heinz Nixdorf Recall study group

\section{Pulmonary vascular disease and interstitial lung disease}

Pulmonary hypertension in idiopathic pulmonary fibrosis with mild-to-moderate restriction Ganesh Raghu, Steven D. Nathan, Juergen Behr, Kevin K. Brown, James J. Egan, Steven M. Kawut, Kevin R. Flaherty, Fernando J. Martinez, Athol U. Wells, Lixin Shao, Huafeng Zhou, Noreen Henig. Javier Szwarcberg, Hunter Gillies, Alan B. Montgomery and Thomas G. O'Riordan

Severe pulmonary hypertension in lung disease: phenotypes and response to treatment Melanie J. Brewis, Alistair C. Church, Martin K. Johnson and Andrew J. Peacock

\section{Pulmonary vascular disease}

New potential diagnostic biomarkers for pulmonary hypertension

Svenja L. Tiede, Henning Gall, Oliver Dörr, Christian Troidl, Christoph Liebetrau, Sandra Voss,

Robert Voswinckel, Ralph T. Schermuly, Werner Seeger, Friedrich Grimminger, Andreas M. Zeiher

Stefanie Dimmeler, Helge Möllmann, Christian W. Hamm, Hossein Ardeschir Ghofrani and Holger M. Nef

\section{Tuberculosis}

Benefit of treatment of latent tuberculosis infection in individual patients

Claudia C. Dobler, Andrew Martin and Guy B. Marks

\section{Respiratory infections}

Cost-effectiveness of adult pneumococcal conjugate vaccination in the Netherlands

Marie-Josée J. Mangen, Mark H. Rozenbaum, Susanne M. Huijts, Cornelis H. van Werkhoven

Douwe F. Postma, Mark Atwood, Anna M.M. van Deursen, Arie van der Ende, Diederick E. Grobbee,

Elisabeth A.M. Sanders, Reiko Sato, Theo J.M. Verheij, Conrad E. Vissink, Marc J.M. Bonten and G. Ardine de Wit

\section{Interstitial and orphan lung disease}

Increased alveolar soluble annexin V promotes lung inflammation and fibrosis

Susan Buckley, Wei Shi, Wei Xu, Mark R. Frey, Rex Moats, Annie Pardo, Moises Selman and David Warburton

\section{Lung transplantation}

Linking clinical phenotypes of chronic lung allograft dysfunction to changes in lung structure

Stijn E. Verleden, Dragos M. Vasilescu, John E. McDonough, David Ruttens, Robin Vos, Elly Vandermeulen, Hannelore Bellon, Rachél Geenens, Erik K. Verbeken, Johny Verschakelen, Dirk E. Van Raemdonck, Wim A. Wuyts, Youri Sokolow, Christiane Knoop, Joel D. Cooper, James C. Hogg, Geert M. Verleden and Bart M. Vanaudenaerde

\section{Lung cancer}

Erlotinib versus carboplatin and paclitaxel in advanced lepidic adenocarcinoma: IFCT-0504 Jacques Cadranel, Radj Gervais, Patrick Merle, Denis Moro-Sibilot, Virginie Westeel, Laurence Bigay-Game, Elisabeth Quoix, Sylvie Friard, Fabrice Barlesi, Claire Lethrosne, Lionel Moreau, Isabelle Monnet, Mathieu Salaun, Gérard Oliviero, Pierre-Jean Souquet, Martine Antoine, Alexandra Langlais, Franck Morin, Marie Wislez and Gérard Zalcman on behalf of the Intergroupe Francophone de Cancérologie Thoracique (IFCT)

\section{Lung biology and experimental studies}

Disruption of pulmonary lipid homeostasis drives cigarette smoke-induced lung inflammation in mice Mathieu C. Morissette, Pamela Shen, Danya Thayaparan and Martin R. Stämpfli 
1461 Efficacy and safety of World Health Organization group 5 drugs for multidrug-resistant tuberculosis treatment

Nicholas Winters, Guillaume Butler-Laporte and Dick Menzies

\section{SERIES}

SERIES “RARE PULMONARY DISEASES AND ORPHAN DRUGS”

Edited by S. Harari and M. Humbert

Number 3 in this Series

1471 The changing face of a rare disease: lymphangioleiomyomatosis

Sergio Harari, Olga Torre, Roberto Cassandro and Joel Moss

\section{AGORA}

\section{Research letters}

1486 Airway eosinophils in older teenagers with outgrown preschool wheeze: a pilot study Lucy Marshall, Caroline S. Beardsmore, Anina M. Pescatore, Claudia E. Kuehni and Erol A. Gaillard

1489 Anti-inflammatory effects of targeted lung denervation in patients with COPD Loes E.M. Kistemaker, Dirk-Jan Slebos, Herman Meurs, Huib A.M. Kerstjens and Reinoud Gosens

1492 Poor agreement between chart-based and objectively identified comorbidities of COPD Filip J.J. Triest, Frits M.E. Franssen, Martijn A. Spruit, Miriam T.J. Groenen, Emiel F.M. Wouters and Lowie E.G.W. Vanfleteren

Continuous fat-free mass decline in COPD: fact or fiction?

Erica P.A. Rutten, Martijn A. Spruit, Merry-Lynn N. McDonald, Stephen Rennard, Alvar Agusti, Bartolome Celli, Bruce E. Miller, Courtney Crim, Peter M.A. Calverley, Corrine Hanson, William MacNee, Frits M.E. Franssen, Lowie Vanfleteren and Emiel F.M. Wouters on behalf of the ECLIPSE (Evaluation of COPD Longitudinally to Identify Predictive Surrogate End-points) Investigators

$1498 \quad$ Diagnosis of COPD before cardiac surgery

Nicholas J. McKeon, Sjane N. Timmins, Heather Stewart, Stephanie T. Yerkovich and James L. McKeon

Low plasma CC16 levels in smokers are associated with a higher risk for chronic bronchitis Hans Petersen, Shuguang Leng, Steven A. Belinsky, Bruce E. Miller, Ruth Tal-Singer, Caroline A. Owen, Bartolome Celli and Yohannes Tesfaigzi

Mefloquine as a potential drug against multidrug-resistant tuberculosis

David Krieger, Silvan Vesenbeckh, Nicolas Schönfeld, Gudrun Bettermann, Torsten Thomas Bauer, Holger Rüssmann and Harald Mauch

Discordance between the QuantiFERON-TB Gold In-Tube and Tuberculin Skin Test: need for a further step? Michele Spinicci, Jessica Mencarini, Delia Goletti, Antonia Mantella, Nunzia Della Malva,

Alessandro Bartoloni and Filippo Bartalesi

1509 Phenotyping chronic pulmonary aspergillosis by cluster analysis

Cendrine Godet, François Laurent, Guillaume Béraud, Cécile Toper, Boubou Camara, Bruno Philippe, Patrick Germaud, Vincent Cottin, Catherine Beigelman-Aubry, Antoine Khalil, Pascal Blouin, Mathilde Pouriel,' France Roblot, Anne Bergeron and Jacques Cadranel for the ACHROSCAN study group

1513 Demand for exercise training in patients with pulmonary arterial hypertension in Scotland Alison MacKenzie and Martin Johnson

$1515 \quad$ How does a new breathlessness support service affect patients?

Marjolein Gysels, Charles C. Reilly, Caroline J. Jolley, Caty Pannell, Femke Spoorendonk, Helene Bellas, Preety Madan, John Moxham, Irene J. Higginson and Claudia Bausewein

\section{Correspondence}

1519 Lung cancer screening white paper: a slippery step forward?

Alberto Ruano-Ravina, Mariano Provencio-Pulla and Alberto Fernández-Villar; Hans-Ulrich Kauczor, Lorenzo Bonomo, Mina Gaga, Kristiaan Nackaerts, Nir Peled, Mathias Prokop, Martine Remy-Jardin, Oyunbileg von Stackelberg and Jean-Paul Sculier on behalf of the European Society of Radiology (ESR) and the European Respiratory Society (ERS)

1523 COPD (confusion over proper diagnosis) in the zone of maximum uncertainty Philip H. Quanjer, Gregg Ruppel, Vito Brusasco, Rogelio Pérez-Padilla, Carlos A. Vaz Fragoso, Bruce H. Culver, Maureen P. Swanney, Martin R. Miller, Bruce Thompson, Mike Morgan, Mike Hughes, Brian L. Graham, Riccardo Pellegrino, Paul Enright, A. Sonia Buist and Peter Burney; Bartolome R. Celli for the authors of the ATS/ERS statement on research questions in COPD

1526 We must join forces in the battle against COPD

Anders Ostrem, Siân Williams and Hilary Pinnock on behalf of the International Primary Care Respiratory Group; Bartolome R. Celli for the authors of the ATS/ERS statement on research questions in COPD

1529 The Rotterdam study: why fall in COPD?

Pampa De and Sourin Bhuniya; Lies Lahousse, Vincentius J.A. Verlinden, M. Arfan Ikram and Guy G. Brusselle 